\title{
On the predictability of volcano-tectonic events by low frequency seismic noise analysis at Teide-Pico Viejo volcanic complex, Canary Islands
}

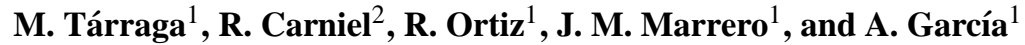 \\ ${ }^{1}$ Departamento de Volcanología, Museo Nacional de Ciencias Naturales, CSIC, C/José Gutierrez Abascal 2, 28 006, Madrid, \\ Spain \\ ${ }^{2}$ Dipartimento di Georisorse e Territorio, Università di Udine, Via Cotonificio, 114, 33100 Udine, Italy
}

Received: 1 December 2005 - Revised: 23 February 2006 - Accepted: 4 March 2006 - Published: 15 May 2006

\begin{abstract}
The island of Tenerife (Canary Islands, Spain), is showing possible signs of reawakening after its last basaltic strombolian eruption, dated 1909 at Chinyero. The main concern relates to the central active volcanic complex Teide Pico Viejo, which poses serious hazards to the properties and population of the island of Tenerife (Canary Islands, Spain), and which has erupted several times during the last 5000 years, including a subplinian phonolitic eruption (Montaña Blanca) about 2000 years ago. In this paper we show the presence of low frequency seismic noise which possibly includes tremor of volcanic origin and we investigate the feasibility of using it to forecast, via the material failure forecast method, the time of occurrence of discrete events that could be called Volcano-Tectonic or simply Tectonic (i.e. non volcanic) on the basis of their relationship to volcanic activity. In order to avoid subjectivity in the forecast procedure, an automatic program has been developed to generate forecasts, validated by Bayes theorem. A parameter called "forecast gain" measures (and for the first time quantitatively) what is gained in probabilistic terms by applying the (automatic) failure forecast method. The clear correlation between the obtained forecasts and the occurrence of (Volcano-)Tectonic seismic events - a clear indication of a relationship between the continuous seismic noise and the discrete seismic events - is the explanation for the high value of this "forecast gain" in both 2004 and 2005 and an indication that the events are Volcano-Tectonic rather than purely Tectonic.
\end{abstract}

\section{Introduction}

Tenerife is the largest island of the Canarian Archipelago (Fig. 1). Eruptions of mantle derived basaltic magmas covering the period between 12 and 3.3 Ma (Ancochea et al.,

Correspondence to: M. Tárraga

(martat@mncn.csic.es)
1990) generated a large composite subaerial shield structure. Contemporaneous with the last episodes of that main basaltic volcanism period eruptions of more differentiated magmas started at the centre of the island forming a central composite volcanic complex, named the Las Cañadas edifice (Araña, 1971). The existence of evolved phonolitic magmas suggests that the history of this edifice in the last $3.5 \mathrm{My}$, can be associated with a series of shallow magma chambers (Martí et al., 1994). The construction of the Las Cañadas edifice was truncated by the formation of the Las Cañadas caldera, which is currently attributed to a series of vertical collapses (Araña, 1971; Martí and Gudmunsson, 2000) that originated a roughly elliptical depression of $16 \mathrm{~km} \times 9 \mathrm{~km}$ (see Fig. 1). Its base lies at about $2000 \mathrm{~m}$ a.m.s.l. and is closed off by a huge wall, visible for $27 \mathrm{~km}$ along the SW, S-SE and NE sectors (Martí et al., 1994).

A double stratovolcano has formed on the northern border of the Caldera over the last 0.18 Ma: the Teide-Pico Viejo system, characterized by a complete basaltic to phonolitic series mostly erupted as lava flows and domes also including some explosive events (Ablay et al., 1995; Ablay and Martí, 2000). The two summits are separated by $2.5 \mathrm{~km}$, the highest altitude $(3718 \mathrm{~m})$ corresponding to the youngest summit of Teide, an approximately circular cone with a basal diameter of about $5 \mathrm{~km}$. Pico Viejo products occupy the western part of the Las Cañadas caldera, while Teide basaltic and phonolitic products are found in the central and northern part of the caldera, covering its northern slopes and infilling the adjacent Icod and La Orotava valleys to the North. The subplinian eruption of Montaña Blanca (Ablay et al., 1995; Ablay and Martí, 2000), about 2000 years b.p., is one of the latest phonolitic events on the southern Teide flank. Several minor eruptions involving basaltic magma have occurred in historical times, the last one in 1909 in Chinyero, near Pico Viejo along the NW-SE ridge, one of the two active rift zones that still control basaltic volcanism on the island (Fig. 1).

Published by Copernicus GmbH on behalf of the European Geosciences Union. 


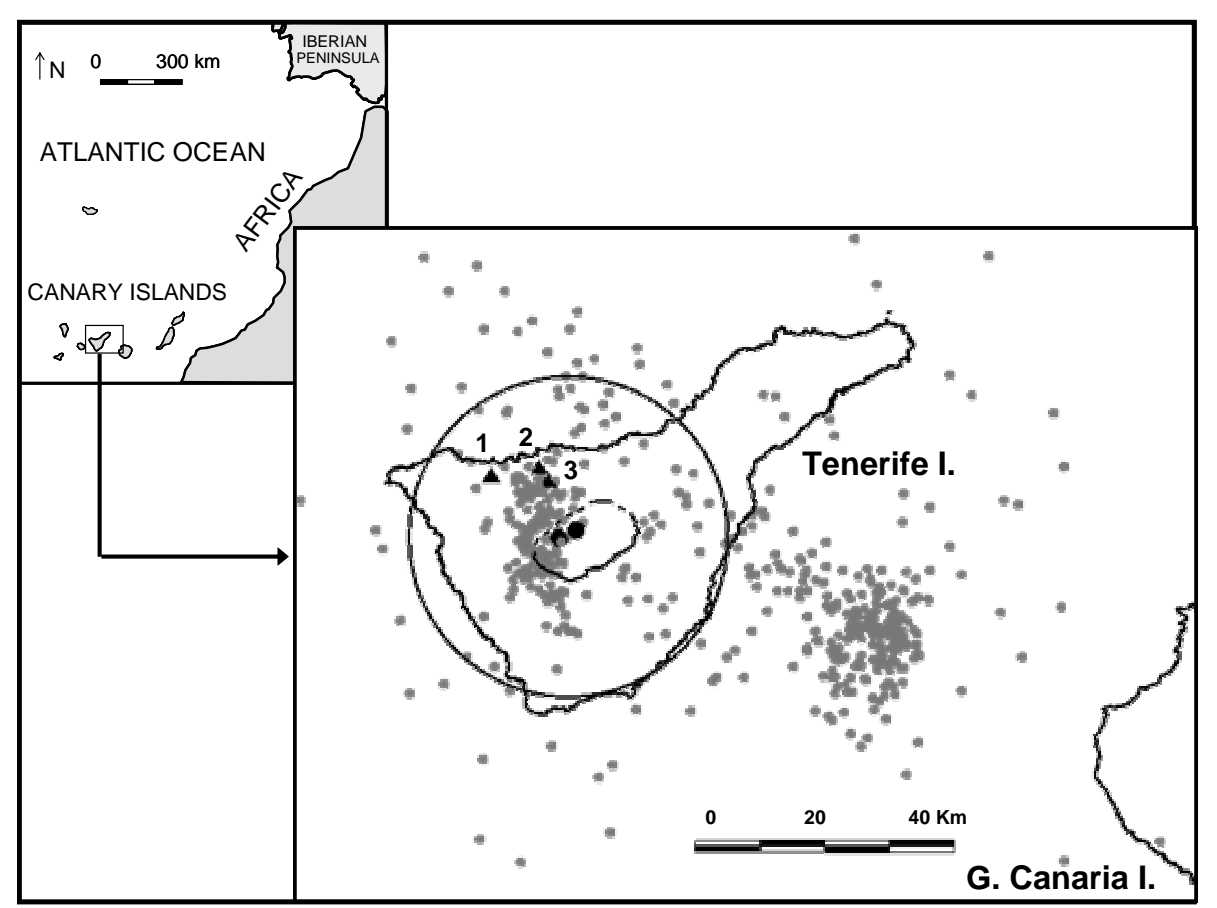

Fig. 1. Map of Tenerife island. The black triangles show the location of the seismic stations (1-TNQ, 2-BDG, 3-GLR). The black dots represent the Teide-Pico Viejo volcanic complex, surrounded by the caldera rim (black line). The grey points show the seismic event as located by the Instituto Geográfico Nacional, Spain. The circle represents the boundary (radius $=25 \mathrm{~km}$ ) along which seismic events "inside" and "outside" the islands are separated to build independent statistics.

A future eruption on Tenerife can be potentially hazardous due to the proximity of populated areas such as the Orotava and Icod Valleys, not protected by a sufficiently high caldera wall. An extensive study (Araña et al., 2000) generated a qualitative hazard map of Tenerife where most probable source areas have been defined to model lava flows paths and ash fall thicknesses. The area with the maximum hazard for both lava and ash covers the inside and surroundings of the Las Cañadas Caldera. The second zone in terms of hazard comprises both the northern flank of the Central Edifice and the northern and most of the southern slopes of the NWSE ridge. The third zone includes the slopes of the southern part of the NE-SW ridge and the great valleys of Güimar and Orotava (Araña et al., 2000).

A series of seismic surveys were conducted in the caldera in the last few years. Mezcua et al. (1992) defined the regional seismicity as moderate, with earthquake magnitudes not exceeding 5.0 and source locations usually offshore towards Gran Canaria. Del Pezzo et al. (1997) analyzed the coda of local earthquakes using two seismic arrays in the eastern part of Las Cañadas, demonstrating the presence of a highly heterogeneous shallow structure producing strong scattering of the seismic waves. The use of seismic antennas allowed Almendros et al. (2000) to find the existence of a moderate tectonic seismicity, local (S-P time between 3 and $5 \mathrm{~s}$ ) and very local (S-P time less than $3 \mathrm{~s}$ ), with three fam- ilies of source locations, i.e. below Teide-Pico Viejo, in the eastern border of the caldera, and offshore. At the same time a lack of any sign of volcanic tremor was highlighted. A strong presence of the oceanic microseismic noise was also highlighted, with main frequencies below $1 \mathrm{~Hz}$, making the authors suggest that a weak volcanic tremor would be difficult to detect due to the low signal-to-noise ratio (Almendros et al., 2000).

An extensive and dense microtremor measurements survey was conducted in the Las Cañadas caldera in 2000 and 2001 (Almendros et al., 2004). A strong peak at $1 \mathrm{~Hz}$ was again interpreted as related to the oceanic noise, while the other most important frequencies in the range $1-10 \mathrm{~Hz}$ were spatially mapped with the Nakamura technique (Nakamura, 1989) in order to detect resonances of subsurface transients, highlighting a noteworthy spatial variability, which can be explained by both S-wave velocity and thickness changes due to the complex superpositions of Teide and PicoViejo deposits in the caldera.

From the seismic point of view, a change was observed first in 2003 and more evidently in 2004, when the spanish national agency Instituto Geográfico Nacional (IGN) started recording, besides the "usual" seismic activity, mainly concentrated in the sea channel between the islands of Tenerife and Gran Canaria, an increasing number of seismic events located within the island of Tenerife (see Fig. 1) (IGN, 
Servidor de Geodesia y Geofísica, http://www.geo.ign.es/, 2005; García et al., 2006). In order to understand the reason for this increment of seismicity, a research project was funded by the Spanish Ministry of Education and Science: TEGETEIDE - Técnicas geofísicas y geodésicas para el estudio de la zona volcánica activa Teide-Pico Viejo, Tenerife, contract CGL2004-21643-E, coordinated by one of the authors, A. García. In this paper we will investigate the time evolution of parameters computed on the seismic noise continuously recorded on the island and relate it to the occurrence of tectonic events, in order to characterize them as purely tectonic or related to the volcanic activity.

\section{Instrumentation and data}

We installed 3 short period seismic stations on the island of Tenerife (BDG -3 components, TNQ and GLR -1 component: see Fig. 1). The acquisition system hardware and software, developed at the Departamento de Volcanología, CSIC, Madrid (Ortiz et al., 2001) is currently operating at other volcanoes including Timanfaya (Lanzarote, Canary Islands, Spain), Sete Cidades (Azores, Portugal), Villarrica and Llaima (Chile) and Stromboli (Italy) (Carniel et al., 2006). The system features an A/D converter based on the AD7710 of Analog Devices with sigma-delta technology with 24 bits resolution, Trimble Lassen II GPS time synchronization and serial connection to a laptop PC, which stores the data and handles, where available, an ADSL internet connection. Data are stored with 16 bits $(96 \mathrm{~dB})$ at a sampling frequency of $50 \mathrm{~Hz}$. Data analysed here were recorded between 1 June 2004 and 30 June 2005.

\section{Data analysis}

We first analysed the time evolution of the seismic intensity and spectral content by subdividing the raw seismic data in windows of 120 s (i.e. 6000 sample points at $50 \mathrm{~Hz}$ ), with a $50 \%$ overlap so that two successive windows are separated by 1 min (Carniel and Di Cecca, 1999). Although more or less evident at the different locations, a clear $24 \mathrm{~h}$ modulation is observed which can be in great part attributed (in particular at the stations closer to the village of Icod) to anthropogenic effects, although meteorology and tides can also play a role.

Another interesting observation is the appearance of low frequency seismic noise episodes that show one or more predominant frequency peaks. The appearance of such episodes supports the hypothesis of a volcanic origin to explain at least part of the energy observed as continuous seismic noise.

The influence of regional - i.e. non-volcanic - tectonic events on the volcanic activity has been observed at some volcanoes (e.g. Ambrym, see Carniel et al., 2003) but it is not evident at other volcanoes (e.g. Stromboli, see Falsaperla et al., 2003). In this paper we aim to investigate the interactions between the tectonic events and the "volcanic tremor" in the opposite way, i.e. can the time evolution of parameters computed on the seismic noise (including volcanic tremor) be used to forecast the occurrence of (volcano-)tectonic events?

We start to tackle this question by introducing the material Failure Forecast Method. The material Failure Forecast Method (FFM) was proposed after the Mt. St. Helens eruption, by Voight (1988, 1989), Voight and Cornelius (1991) and Cornelius and Voight (1995) based on the hypothesis that the growth of magma paths is driven by rock failure in the edifice induced by overpressure in the magma chamber. Although this hypothesis is not always supported by the statistics (Chastin and Main, 2003), recent examples of successful applications to explosive activity include the volcanoes Colima (De la Cruz-Reyna and Reyes-Dávila, 2001) and Villarrica (Ortiz et al., 2003). Although an example exists where the method has been applied to the hindcast of a paroxysmal phase at Stromboli volcano (Carniel et al., 2006), no published examples of successful application of the method to the forecast of the onset of basaltic effusive eruptions are known to the authors. At Tenerife, the successful application of the FFM methodology (that usually doesn't work in the case of effusive eruptions) may therefore provide indirect evidence against the hypothesis of a quiet basaltic eruption as the evolution of the ongoing crisis.

The idea is to study the acceleration of the growth of an observable by monitoring its inverse, in order to forecast more easily (with the intersection with the zero axis rather than with the approximation of a "sufficiently high value") the occurrence of an event. In our case the observable is the RSEM (Real-time Seismic Energy Measurement). The formulation we use is similar to the original RSAM (Realtime Seismic Amplitude Measurement) proposed by Endo and Murray, 1991, where the squared intensity is used instead of the simple modulus. We also use a derived parameter called SSEM, analogous to the SSAM (Rogers and Stephens, 1995), where also the contribution of the different frequency bands is taken into account. In other words, RSEM measures the total seismic energy recorded by a seismometer, while SSEM only weights the energy irradiated in "useful" frequency band(s), in order to exclude from the count those frequencies that are most probably associated with other phenomena, like anthropogenic or meteorological noise. In our case we examine both the RSEM computed over the raw data, and the SSEM computed over a band-pass filtered signal (Finite Impulse Response FIR, center frequency $1.2 \mathrm{~Hz}$, attenuation $-80 \mathrm{~dB}$ at 0.5 and $2 \mathrm{~Hz}$ ). The window length we use in this case is $10 \mathrm{~min}$. The filter is designed from the spectrogram in order to optimize the stability of 1/RSEM or $1 /$ SSEM on one side and its sensitivity to changing volcanic activity on the other.

In Fig. 2 we show an example, where the dashed vertical line marks a seismic swarm including a $\mathrm{M}=2.3$ event (as estimated by IGN, Instituto Geográfico Nacional) on the $3 \mathrm{Au}-$ gust 2004, 05:23:19 h. In this case many descending trends of the band-pass filtered 1/SSEM can be fitted in order to 


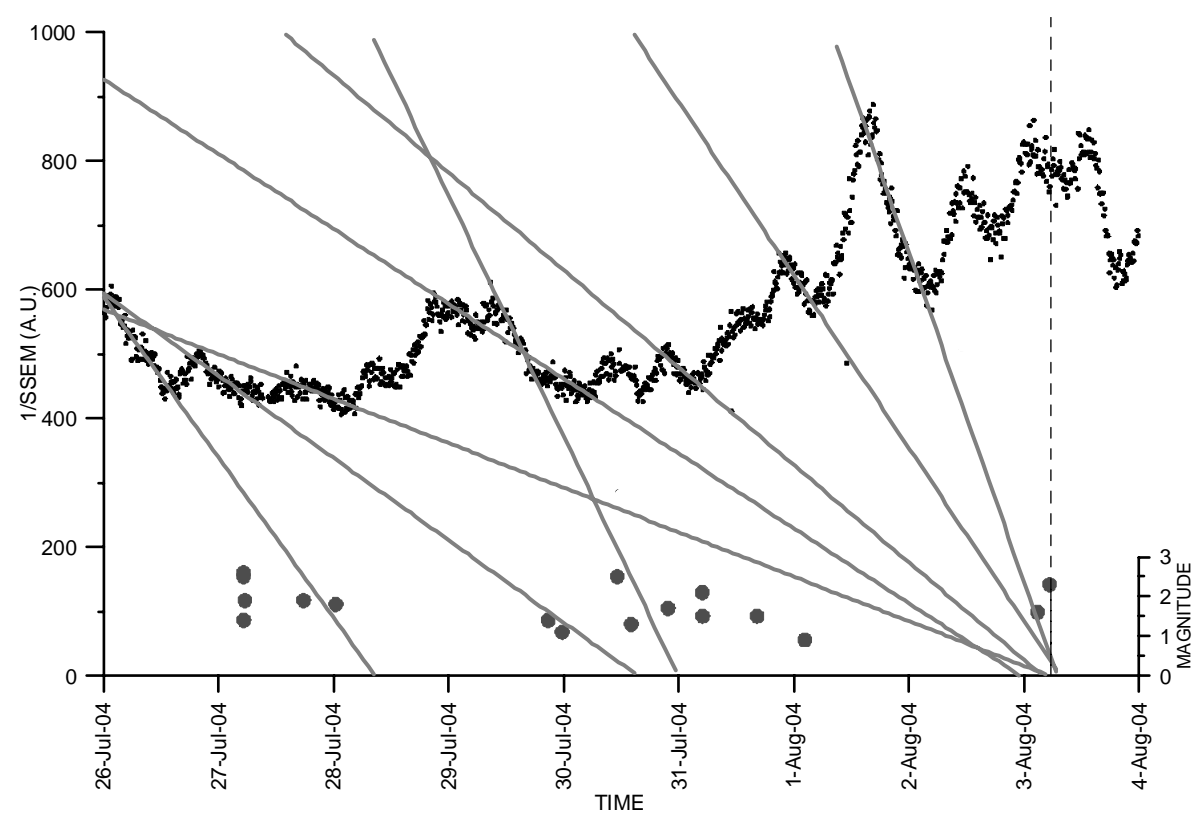

Fig. 2. Example of application of the material Failure Forecast Method to the forecast of the seismic swarms of 27 July, 30-31 July and 3 August. The 1/SSEM is computed over a band-pass filtered signal (Finite Impulse Response FIR, center frequency $1.2 \mathrm{~Hz}$, attenuation $-80 \mathrm{~dB}$ at 0.5 and $2 \mathrm{~Hz}$ ). Several fits are presented; note that for the 3 August swarm (dashed vertical line) the fits give in general better forecasts as the time of the event is approached. Grey dots indicate tectonic events, with vertical height related to the magnitude as estimated by Instituto Geográfico Nacional (scale on the right). For descending trends for which the intersection of the line with the zero axis (i.e. the forecasted time) goes beyond 4 August (limit of the horizontal time axis) the line is not drawn.

find a forecast with the intersection with the zero axis, giving better and better forecasts as we get closer to the time of occurrence of the events.

Many other examples are observed where the 1/SSEM can be used to forecast the time of occurence of events or events swarms, suggesting that, notwithstanding the presence of a significant anthropogenic and sea microseism contribution to the recorded seismic noise, this still contains a sufficiently high component that can be attributed to a volcanic origin.

However, as can be clearly seen in Fig. 2 observing the lines fitted to the data during the last days of July 2004, there is a considerable amount of subjectivity in the choice of the parameters involved in the generation of each FFM forecast.

As a result efforts were made to develop an automated algorithm to produce and evaluate these forecasts. In the next section we will introduce this automatic procedure and then statistically compare the forecast produced with the occurrence of tectonic events. A forecast is declared successful if the time difference between the forecasted and real event is less than $24 \mathrm{~h}$. Of course this is somehow an arbitrary choice, out of a compromise between unavoidable uncertainties in the forecast time (suggesting a longer window of "alert") and usefulness of the forecast (suggesting a shorter window of "alert").

\section{Automatization of the FFM}

Being evident a rather strong $24 \mathrm{~h}$ cyclic component, we applied a Seasonal-Trend decomposition of time series based on Loess (Cleveland et al., 1990), an iterative procedure that allows to separate the original signal (in this case the SSEM) into a seasonal component, a trend component and a remainder component (Fig. 3). Maxima in the trend part of the decomposed 1/SSEM time series are sought and the following decreasing part is used to fit a decreasing linear trend and determine, by the crossing with the zero axis, the forecast times. Although a high number of potential forecasts are generated, only few of them are accepted, i.e. the ones that fulfill specific requirements: a minimum number of data points in the decreasing section, a minimum quality of the fit in the least square sense, a maximum time difference between the maximum that initiates the decrease and the zero crossing that ends it (or, equivalently, a minimum decreasing slope). The choice of which forecasts to accept is completely automatic, without any human intervention. Of course parameters values in the criteria above can be used to fine tune the performances. The first problem to be solved is how to decide when to start a decreasing fit. The most natural choice was to start fitting a decrease at a maximum. After studying and comparing different situations, we highlighted two different methods to carry out the choice of such a maximum. Please note that 


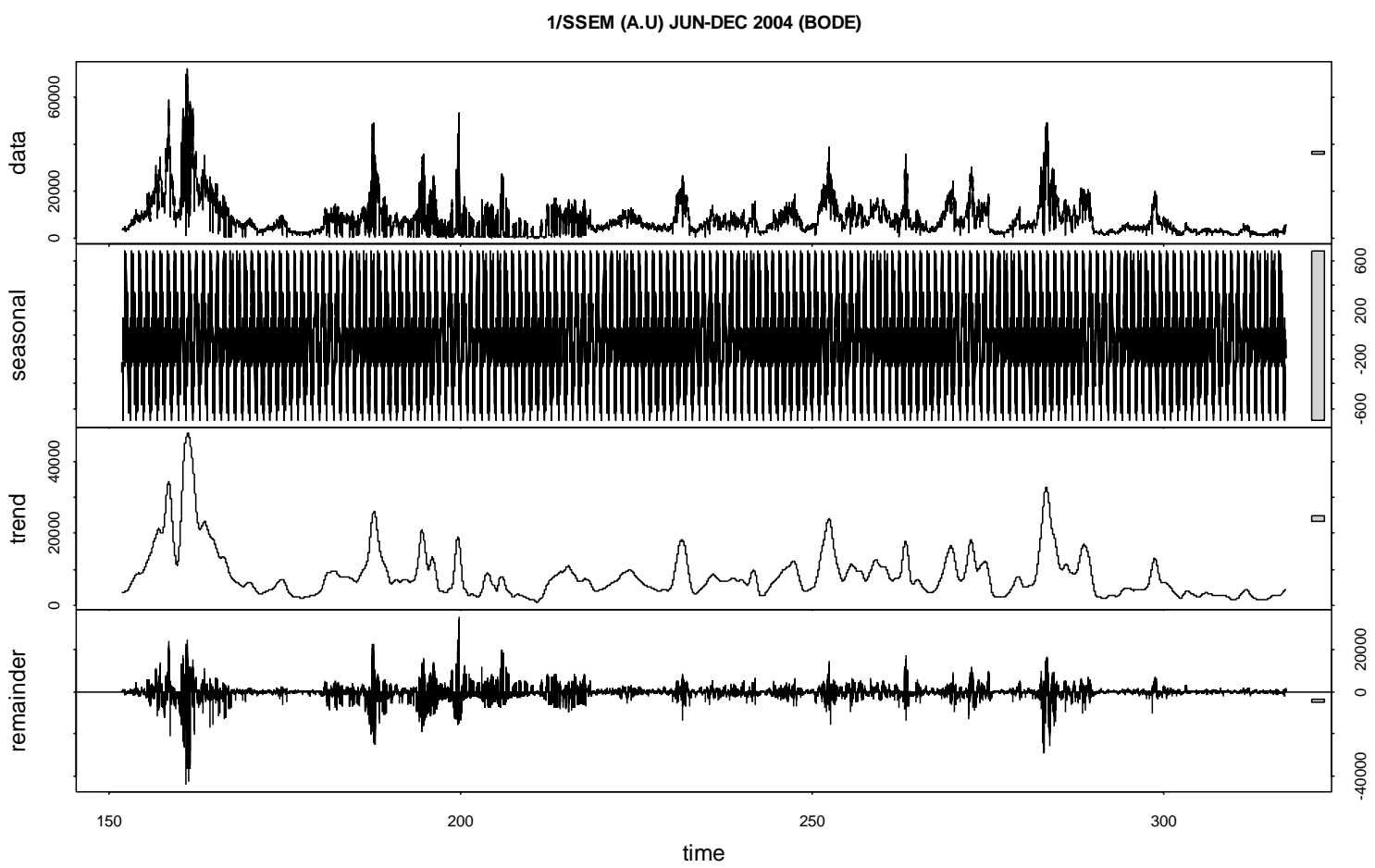

Fig. 3. Example of application of the Loess seasonal decomposition to the time evolution of the inverse of the SSEM for the period JuneDecember 2004. The original signal (at the top) is decomposed into a seasonal, a trend and a remainder components. Note the different vertical scales, also indicated by the grey rectangles on the right. Only the trend component is used in the following FFM analysis.

not all fits generated at this stage will make it to the final stage, as they have to fulfil further conditions later on.

[Max_A] choose any local relative maximum, i.e. choose any point which value is greater than the value immediately before in time and greater than the value immediately after.

[Max_B] choose a maximum in a $6 \mathrm{~h}$ long time window. This is of course a much more stringent condition, that strongly affects the number of fits generated but may of course increase their average forecasting potential.

In Fig. 4 an example can be seen of how an automatic fit is generated. For both cases presented above (Max_A and Max_B), more requirements are imposed in order to further generate or accept a forecast. In every descending trend following the maximum, a minimum number of 144 data points have to be used, corresponding to a duration of $24 \mathrm{~h}$. This, together with the seasonal decomposition already cited, aims to avoid the generation of forecasts based on a descent that maybe ascribed to anthropogenic origins. This minimum duration is indicated by the letter D in Fig. 4. In order to guarantee that the descending trend is "really descending" a minimal quality of the linear fit is required in a least square sense, rejecting any fit with a quality less than 0.8 .
After having generated (and perhaps accepted on the base of the least squares quality) the first fit using the minimum number of data points, other fits are successively generated starting from the same maximum. This is done by adding 50 data points at each step. Referring to Fig. 4, this corresponds to enlarging the duration of the period $\mathrm{D}$ by $8.33 \mathrm{~h}$ each time. In an analogous way to the required minimum of 144 points, a maximum is also imposed on this number of data points, equal to 576, which corresponds to 4 days. This limit is imposed to stop the generation of forecasts from a given maximum in the statistical hind-cast exercise conducted in this paper, but could be removed when applying the methodology in the real-time analysis of seismic data. There is a final condition to be satisfied in order to accept the forecast before comparing it to the occurrence of a seismic event, i.e. that the time difference between the moment when the forecast is issued and the time of the forecasted time for the event must be more than $10 \mathrm{~h}$. This has a double reason: the first is to ensure that the forecast is not issued immediately before the event (which would be of doubtful use), the second is that a shorter timescale would not be coherent with the choice of evaluating a forecast as "successful" if it falls within $24 \mathrm{~h}$ from a seismic event. 


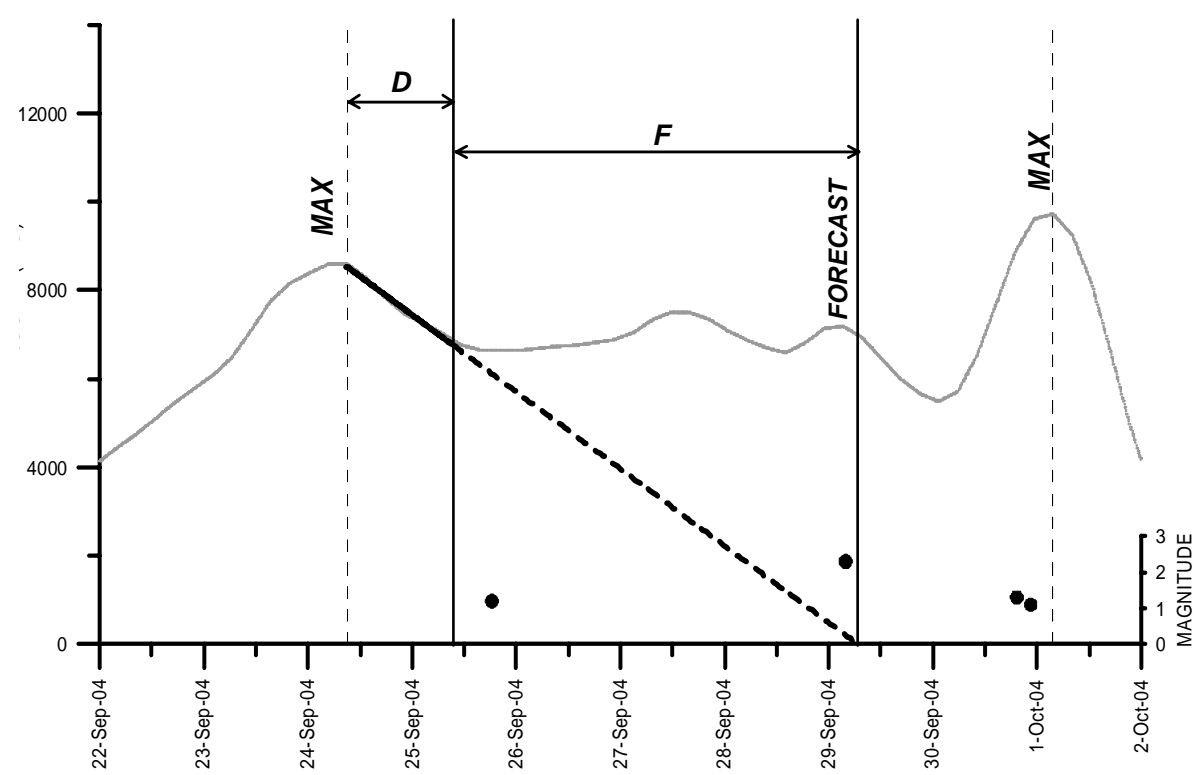

Fig. 4. Example of a successful automatic forecast. The black dots represent the seismic events (with their magnitudes as computed by IGN). The vertical dashed lines represent automatically detected maxima according to rule Max_B (each is a local maximum with respect to a time window of $6 \mathrm{~h}$ ) that generate an accepted forecast according to the criteria described in the text. $D$ is the minimum number of data points 144 - required to generate the first fit, corresponding to a time window of 1 day, that will be expanded, adding 50 points at a time, until a maximum number of data points of 576 (corresponding to 4 days). $F$ represents the time difference between the generation of the forecast and the time of the forecast itself. In this case the forecast was issued 3.8 days in advance, close to the maximum allowed number of data points, which corresponds to 4 days.

\section{Results}

If we consider only the days with a seismic event, in the year 2004 the $60.24 \%$ (in the case max_A) and $56.63 \%$ (case max_B) of them is correctly forecasted. However, this apparently promising result must be evaluated very carefully. It is in fact very easy to reach a $100 \%$ percentage of success by removing any one of the conditions on the fits imposed above. This however would increase unacceptably the number of the false alarms; it is sufficient to consider the extreme limit of declaring a forecast every single day: $100 \%$ forecast success but a number of false alarms that would convert the forecast into something completely useless. We therefore compute a more complete statistics, involving all days (214 days in 2004 and 181 in 2005) of seismic data acquisition at BDG, showing the distribution of all the 4 combinations of "occurrence of at least a seismic event" (EVENT YES/ EVENT NO) and "issue of at least a forecast" (FORECAST YES/ FORECAST NO). This is done for the two cases max_A and max_B and evaluated for different periods of time, in order to evaluate if a significantly different behaviour can be observed in 2004 and 2005 and/or analyzing the period with the highest level of seismic activity (Period "E" of 2004). The two months of June 2004 and June 2005 are also compared, where the best meteorological conditions can be assumed. All of these results are presented in Table 1.
The first two columns of Table 1 evaluate the percentage of days with seismic activity that we can successfully forecast. The comparison of the full period June-December 2004 ( $60.24 \%$ of forecasted events, as already noted above) with the period of maximum activity "E", between 25 July and 7 September 2004 (75.86\% of forecasted events) immediately highlights another problem of this kind of statistics. The apparently better result achieved during the period " $E$ " is in fact an artefact of the statistics: even if we tossed a coin to issue a forecast, when we have more events (period E), the probability of forecasting an event naturally increases. On the contrary, the apparently worse results related to case Max_B respect to the case Max_A have to be evaluated also by the comparison with the number of false alarms. This can only be done by looking at the last 4 columns with a Bayesian approach.

From a feasibility of application point of view, we see in Table 1 the number of false alarms as the major problem $(20.56 \%$ in the worst case, relative to the period JuneDecember 2004). In order to properly weight the (negative) importance of this problem with respect to the (positive) advantages of issuing such forecasts, let's examine if the added evidence of having an issued forecast changes effectively the probability of having the occurrence of a seismic event. To do this, we use Bayes' formula:

$P(H \mid E)=P(H) \frac{P(E \mid H)}{P(E)}$ 
Table 1. Evaluation statistics for the application of the fully automatic version of the material Failure Forecast Method. Column PERIOD indicate different time windows over which the statistics are evaluated. Column CASE Max_ indicate the criterion with which a maximum is chosen to start the forecast generation (see text for further details).

Columns "\% Forec" and "\% Not Forec" under the headline "Total days with events" show the percentage of Forecasted and Not Forecasted days out of the total number of days with at least a seismic event. The other 4 columns represent the percentages of the 4 combinations of the "occurrence of at least a seismic event" (EVENT YES/ EVENT NO) and "issue of at least a forecast" (FORECAST YES/ FORECAST $\mathrm{NO})$ :

$\%$ FORECASTED EVENTS = EVENT YES \& FORECAST YES (Success)

$\%$ FORECASTED "NO EVENTS" = EVENT NO \& FORECAST NO (Success)

$\%$ FALSE ALARMS = EVENT NO \& FORECAST YES (Fail)

$\%$ NOT FORECASTED EVENTS = EVENT YES \& FORECAST NO (Fail).

\begin{tabular}{|c|c|c|c|c|c|c|c|}
\hline \multirow{3}{*}{ Period } & \multirow{3}{*}{$\begin{array}{l}\text { Case } \\
\text { Max }_{-}\end{array}$} & \multicolumn{2}{|c|}{ Total days with events } & & \multirow{2}{*}{$\%$ FORECASTED } & \multirow{3}{*}{$\begin{array}{l}\% \text { FALSE } \\
\text { ALARMS }\end{array}$} & \multirow{3}{*}{$\begin{array}{c}\% \text { NOT } \\
\text { FORECASTED } \\
\text { EVENTS }\end{array}$} \\
\hline & & $\%$ FOREC & $\%$ NOT & & & & \\
\hline & & & FOREC & FORECAST.EVENTS & “NO EVENTS" & & \\
\hline June-Dec 2004 & A & 60.24 & 39.76 & 23.36 & 40.65 & 20.56 & 15.42 \\
\hline June 2004 & A & 36.36 & 63.64 & 13.33 & 60.00 & 3.33 & 23.33 \\
\hline E (days 206-250 2004) & A & 75.86 & 24.14 & 48.89 & 28.89 & 6.67 & 15.56 \\
\hline Jan-June 2005 & A & 46.67 & 53.33 & 15.47 & 44.20 & 22.65 & 17.68 \\
\hline June 2005 & A & 30.77 & 69.23 & 13.33 & 46.67 & 10.00 & 30.00 \\
\hline June-Dec 2004 & B & 56.63 & 43.37 & 21.96 & 45.33 & 15.89 & 16.82 \\
\hline June 2004 & B & 36.36 & 63.64 & 13.33 & 60.00 & 3.33 & 23.33 \\
\hline $\mathrm{E}$ (days 206-250 2004) & B & 58.62 & 41.38 & 37.78 & 26.67 & 8.89 & 26.67 \\
\hline Jan-June 2005 & B & 43.33 & 56.67 & 49.72 & 14.36 & 17.13 & 18.78 \\
\hline June 2005 & B & 46.15 & 53.85 & 53.33 & 20.00 & 3.33 & 23.33 \\
\hline
\end{tabular}

To illustrate the idea, suppose we have two boxes full of balls. Box 1 contains 10 black balls and 30 white balls, while Box 2 has 20 of each. We select a box at random, then a ball at random. The result (Datum, or Evidence E) is "white ball". What is the probability that it came out of Box 1 (Model, or Hypothesis $\mathrm{H}$ )? $\mathrm{P}(\mathrm{H})$ is clearly $1 / 2$, as the boxes are equal. $\mathrm{P}(\mathrm{E})$ is $50 / 80$ (total white balls / total balls). $\mathrm{P}(\mathrm{E} \mid \mathrm{H})$ is $30 / 40$ (white balls in Box $1 /$ total balls in Box 1). Applying the Eq. (1) the answer turns out to be $\mathrm{P}(\mathrm{H} \mid \mathrm{E})=(1 / 2) \times(30 / 40) /(50 / 80)=3 / 5$, which confirms and quantifies the intuition that seeing a white ball gives more confidence to the model "Box 1" which contains a greater number of white balls.

Going back to our case, our Hypothesis $\mathrm{H}$ is defined as a "day with a seismic event" and the Evidence E is defined as a "day with issued forecast". Our prior probability $\mathrm{P}(\mathrm{H})$ can be estimated by dividing the number of days with an event by the total number of days. In the same way we can estimate a probability $\mathrm{P}(\mathrm{E})$ of having a forecast issued and a conditioned probability $\mathrm{P}(\mathrm{E} \mid \mathrm{H})$, so that we arrive to a posterior probability $\mathrm{P}(\mathrm{H} \mid \mathrm{E})$ of having a seismic event given that we have issued a forecast. Of course with the application of the forecast procedure we "gain something" if and only if the posterior probability $\mathrm{P}(\mathrm{H} \mid \mathrm{E})$ that we have on a "forecasted day" is greater than the prior probability $\mathrm{P}(\mathrm{H})$ we can have on "any" day. In other words, a reasonable and fair way to evaluate our forecast procedure is to look at the ratio between these two numbers, i.e. to the quantity $\mathrm{P}(\mathrm{H} \mid \mathrm{E}) / \mathrm{P}(\mathrm{H})=\mathrm{P}(\mathrm{E} \mid \mathrm{H}) / \mathrm{P}(\mathrm{E})$, which we will call forecast gain, and which should be as great as possible, and in any case greater than 1 if we want to "gain something" by issuing the forecast. The results of this Bayesian analysis can be seen in Table 2 for the case Max_A and for the case Max_B.

If we consider the forecast gain as the evaluation parameter, we see that for both complete years 2004 and 2005 the best results are obtained by applying the case Max_B for the choice of the maximum to start the fit(s). The main reason is that choosing the maximum within time windows of $6 \mathrm{~h}$ instead of looking at really "local" time variations reduces the number of false alarms and therefore leads to a better applicability of the whole forecast method.

It is very interesting to examine the cases of June 2004 and June 2005. In Table 1 we see that the percentage of forecasted events is much less than the percentage of nonforecasted events. As already discussed, this apparently very bad performance has to be weighted also taking into account the number of false alarms, that in this case is in fact very low, i.e. very good. The final result is that we pass, e.g. for June 2004 - cases Max_A and Max_B give in this month the same results - from a prior probability of 0.37 to a posterior probability of 0.80 , with a net "forecast gain" factor of 2.18 , the highest ever. Also the case Max_B for June 2005 gives an impressive forecast gain of 1.98 , going from a prior probability of 0.43 to a posterior probability of 0.85 . So, for these two months we can say that, although we issue very few forecasts - and therefore we do not forecast many events - when we 


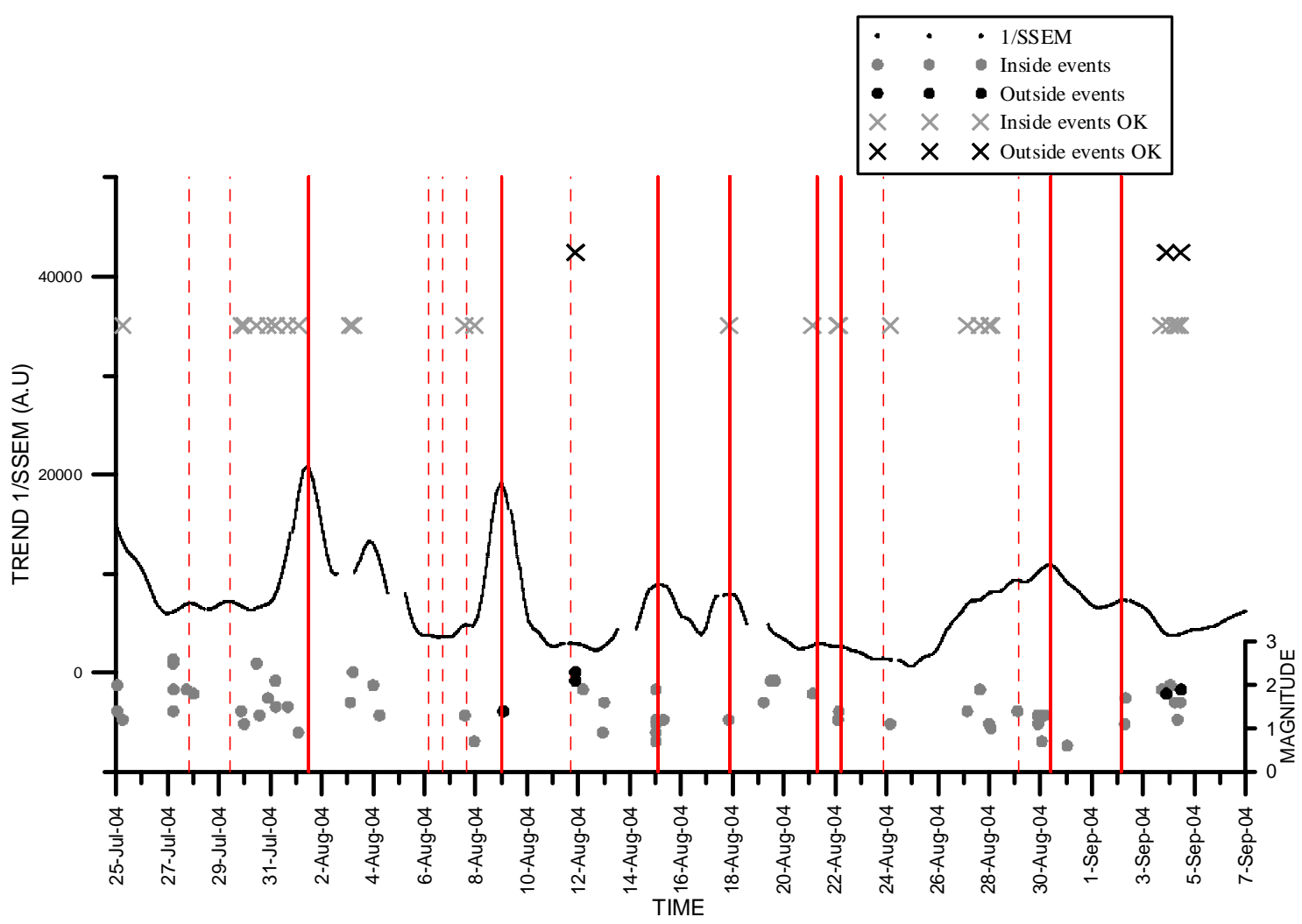

Fig. 5. Trend of the inverse of the SSEM during the time interval with the maximum seismic activity (E: 25 July-7 September 2004). The vertical lines indicate the maxima from which fits are generated according to rule Max_B (each is a local maximum with respect to a time window of $6 \mathrm{~h}$ ). Among these, the continuous lines indicate the maxima that successfully forecast a day with an event. The grey dots indicate the seismic events (with their magnitudes as computed by IGN, scale on the right) that are located inside the island, while black dots indicate events located outside the island. The criterion of separation is the $25 \mathrm{~km}$ circle shown in Fig. 1 . In the top part of the graphs, crosses indicate successfully forecasted events: again, grey crosses indicate inside events, while black crosses indicate outside events.

do issue a forecast we have a very high probability of being successful and a very low probability of incurring into a false alarm.

On the contrary, if we now look at the interval with the maximum seismic activity "E", in both cases Max_A and Max_B the forecast gain is relatively low (1.36 and 1.26). This means that, being the level of activity very high and therefore having a good probability of issuing a successful forecast even by tossing a coin - as there are events almost every day - we do not gain much by carrying out a formal forecast procedure. However, even in this "relatively bad" case, it is important to stress the fact that we still "gain something", as the forecast gain is still greater than 1. By issuing the forecast we increase the probability of being successful (already high) by a further 36 or $26 \%$ respectively.

We now take into account another parameter, i.e. the location of the forecasted events. We can make a first subdivision between events located inside and outside the island. The events belonging to the first class, using a classical definition where volcanic earthquakes are simply defined as earthquakes which occur at or near volcanoes (McNutt, 1996), would be immediately classified as Volcano-Tectonic (VT) events. The events of the second class, on the contrary may or may not be considered "near" volcanoes and can therefore called Volcano-Tectonic or simply Tectonic (i.e. non volcanic) as a result. As a practical and objective way of distinguishing the two classes, we consider as "internal" events the ones that are located within a circle centred in the centre of the caldera and with a radius of $25 \mathrm{~km}$ (see Fig. 1), while we consider as "external" events the ones located outside this circle but inside another circle, with the same centre and a radius of $75 \mathrm{~km}$. Again, these are arbitrary, but reasonable choices related to the geometry of the island (see Fig. 1). Seismic events located outside this second circle do not enter our statistics at all. In Fig. 5 the period of highest activity "E" is shown as an example where the successful forecasts of the two classes of events can be compared, while the complete statistical results are presented in Table 3. It is important to underline that, although the automatic procedure for generating the forecasts is exactly the same as described above, the statistics presented here (i.e. the evaluation of the generated forecasts) are made on the basis of the single seismic events 
Table 2. Bayesian statistical evaluation of the application of the fully automatic version of the material Failure Forecast Method. Column PERIOD indicate different time windows over which the statistics are evaluated. Column CASE Max _ indicate the criterion with which a maximum is chosen to start the forecast generation (see text for further details). The following columns represent the different probabilities involved in the Bayesian evaluation: $\mathrm{P}(\mathrm{H})$ is the a priori probability of the occurrence of a seismic event (our hypothesis $\mathrm{H})$; $\mathrm{P}(\mathrm{E})$ is the probability of issuing a forecast (our evidence $\mathrm{E}$ ); $\mathrm{P}(\mathrm{E} \mid \mathrm{H})$ is the a posteriori probability of issuing a forecast, conditioned to the occurrence of a seismic event; $\mathrm{P}(\mathrm{H} \mid \mathrm{E})$ is the a posteriori probability of the occurrence of a seismic event, conditioned to the existence of an issued forecast; $\mathrm{P}(\mathrm{E} \mid \mathrm{H}) / \mathrm{P}(\mathrm{E})$ is the "forecast gain", i.e. what we gain passing from the a priori probability $\mathrm{P}(\mathrm{E})$ to the a posteriori probability $\mathrm{P}(\mathrm{E} \mid \mathrm{H})$ thanks to the application of the FFM forecast and the consequent issuing of a forecast $\mathrm{H}$.

\begin{tabular}{ccccccc}
\hline Period & CASE Max_ & $\mathrm{P}(\mathrm{H})$ & $\mathrm{P}(\mathrm{E})$ & $\mathrm{P}(\mathrm{E} \mid \mathrm{H})$ & $\mathrm{P}(\mathrm{H} \mid \mathrm{E})$ & $\mathrm{P}(\mathrm{E} \mid \mathrm{H}) / \mathrm{P}(\mathrm{E})$ \\
\hline June-Dec 2004 & A & 0.39 & 0.44 & 0.60 & 0.53 & 1.37 \\
June 2004 & $\mathrm{A}$ & 0.37 & 0.17 & 0.36 & 0.80 & 2.18 \\
E (days 206-250 2004) & $\mathrm{A}$ & 0.64 & 0.56 & 0.76 & 0.88 & 1.36 \\
Jan-June 2005 & $\mathrm{A}$ & 0.33 & 0.38 & 0.47 & 0.41 & 1.22 \\
June 2005 & $\mathrm{A}$ & 0.43 & 0.23 & 0.31 & 0.57 & 1.32 \\
June-Dec 2004 & $\mathrm{B}$ & 0.39 & 0.39 & 0.57 & 0.58 & 1.50 \\
June 2004 & $\mathrm{B}$ & 0.37 & 0.17 & 0.36 & 0.80 & 2.18 \\
E (days 206-250 2004) & $\mathrm{B}$ & 0.64 & 0.47 & 0.59 & 0.80 & 1.26 \\
Jan-June 2005 & $\mathrm{B}$ & 0.33 & 0.31 & 0.43 & 0.45 & 1.38 \\
June 2005 & $\mathrm{B}$ & 0.43 & 0.23 & 0.46 & 0.85 & 1.98 \\
\hline
\end{tabular}

Table 3. Statistical evaluation of the application of the fully automatic version of the material Failure Forecast Method as a function of the location of the forecasted event according to the $25 \mathrm{~km}$ circle shown in Fig. 1. Column PERIOD indicate different time windows over which the statistics are evaluated. Column CASE Max_ indicate the criterion with which a maximum is chosen to start the forecast generation (see text for further details). The first two columns of data (under the heading FORECASTED EVENTS) show the repartition of the forecasted events between the two percentages \% INSIDE ISLAND and \% OUTSIDE ISLAND. The following four columns, under the headings INSIDE EVENTS and OUTSIDE EVENTS, present respectively the percentage of successful (\% FOREC.) and non successful (\% NOT FOREC.) forecasts of each of the two geographically separated classes. Note that this statistics is built from the single events, not from the days with events, so that none of these columns are directly comparable with data contained in Table 1 or Table 2.

\begin{tabular}{cccccccc}
\hline Period & CASE Max & \multicolumn{2}{c}{ FORECASTED EVENTS } & \multicolumn{2}{c}{ INSIDE EVENTS } & \multicolumn{2}{c}{ OUTSIDE EVENTS } \\
& & \% INSIDE & $\%$ OUTSIDE & $\%$ & $\%$ NOT & $\%$ FOREC. & $\%$ NOT \\
& & ISLAND & ISLAND & FOREC. & FOREC. & FOREC. \\
\hline June-Dec 2004 & A & 75.00 & 25.00 & 61.54 & 38.46 & 61.54 & 38.46 \\
June 2004 & A & 58.33 & 41.67 & 50.00 & 50.00 & 50.00 & 50.00 \\
E (days 206-250 2004) & A & 92.45 & 7.54 & 73.13 & 26.86 & 80.00 & 20.00 \\
Jan-June 2005 & A & 47.22 & 52.78 & 45.95 & 54.05 & 41.30 & 58.70 \\
June 2005 & A & 42.86 & 57.14 & 42.86 & 57.14 & 30.77 & 69.23 \\
June-Dec 2004 & B & 72.15 & 27.85 & 48.72 & 51.28 & 56.41 & 43.59 \\
June 2004 & B & 61.54 & 38.46 & 57.14 & 42.86 & 50.00 & 50.00 \\
E (days 206-250 2004) & B & 90.00 & 10.00 & 52.94 & 47.06 & 66.67 & 33.33 \\
Jan-June 2005 & B & 52.94 & 47.06 & 48.65 & 51.35 & 34.78 & 65.22 \\
June 2005 & B & 50.00 & 50.00 & 71.43 & 28.57 & 38.46 \\
\hline
\end{tabular}

and not cumulated over the days, as we could have both inside and outside events during the same day. For this reason, the numbers in Table 3 are not directly comparable to the ones presented in Table 1.

During the entire period June-December 2004, out of the total number of forecasted events with e.g. Max_A methodology, $75 \%$ are located inside the $25 \mathrm{~km}$ radius boundary, $25 \%$ outside it. However, this is just a consequence of the rela- tive distribution of the total number of events, that in 2004 have been concentrating in the inside zone. The numbers for 2005 appear in fact more equally distributed between the two zones.

In order to have a more meaningful statistics, we need therefore to examine the two families of events separately, to derive percentages of successful forecasts that become independent of the relative distribution between the two families. 
This is done in the last 4 columns of Table 3. The result of this analysis is very clear: although percentages change slightly between the different periods, the percentages of forecasted events within the "inside events class" and within the "outside events class" are strikingly similar. The only difference appears in the period June 2005, especially in the case Max_B, but this may be not necessarily be significant. The general result is therefore that the percentages for the two classes "inside" and "outside" the caldera do not differ substantially, i.e. the occurrence of both classes of events can be forecasted using the seismic noise and are therefore related to it, and to one another. The inter-relation between the time of occurrence of the two classes of events represents another interesting subject of research and is being investigated (Marrero et al., 2005).

\section{Discussion and conclusions}

The analysis of seismic signals recorded at 3 different stations (BDG, TNQ, GLR) during the period 1 June 2004-30 June 2005 highlighted the presence of a continuous seismic noise. In agreement with what was previously observed by Almendros et al., 2000, a strong presence of the oceanic microseismic noise was observed, with main frequencies below $1 \mathrm{~Hz}$. It's important to note that no volcanic tremor was observed by Almendros et al., 2000, who also suggested that a weak volcanic tremor would be difficult to detect due to the low signal-to-noise ratio. In our case, the situation is even more difficult as, being our stations closer to inhabitated areas with respect to the ones used in the previous study, the anthropogenic contribution is definitely not negligible. Notwithstanding this, we observe that the time of occurrence of some tectonic events can be forecasted by using a parameter (the band-passed version of the inverse of the RSEM, i.e. 1/SSEM) computed from the seismic noise by using the material Failure Forecast Method. For this reason, it is fully justified to call this seismic noise "tremor". Of course an important question is: When did this tremor begin? According to published data, its appearance is to be postulated between 2001 and early 2004. Preliminary analysis of other seismic array data recorded in the caldera can date back the start of the tremor to 2002 (J. Ibáñez, 2004, personal communication).

An easy criticism of the FFM is related to its subjectivity. For this work, a fundamental step was the development of a fully automatic program that allowed us to eliminate completely the subjectivity of application. This has allowed to carry out a proper statistical analysis, and to evaluate the results in a Bayesian sense. In particular, the parameter "forecast gain" was introduced as the final evaluator. A forecast gain greater than 1 simply means that we do gain something by applying the forecast procedure, i.e. that in the days where a forecast is issued we do have a greater probability of having the occurrence of a seismic (volcano-)tectonic event than what we would obtain in any day, by simply applying the prior statistics on the number of days with events. It is noteworthy that in all of the periods examined in this paper, we always observe a forecast gain greater than 1 . Several attempts have been carried out in order to optimize the forecast gain, e.g. by changing the rules according to which a maximum in the inverse of the SSEM is chosen as a generator for a (series of) decreasing lines and finally a (series of) forecasts. The best results have been obtained using the method Max_B, which chooses this maximum in time windows of $6 \mathrm{~h}$. In particular, this choice produces a significant decrease of the number of false alarms. Moreover, for what concerns the false alarms, we may consider our results conservative, as the catalogue of events we are using is probably not complete due to the level of anthropogenic noise that affects the daylight measurements and that may prevent the detection of some event (thus resulting in an inexistent false alarm if a forecast was issued for that day). We also think that an optimal choice of the several parameters that constrain the automatic fitting procedure, that up to now have been chosen manually - but once selected do not of course affect the full automatization of the forecast issuing procedure - still gives the opportunity to improve the results. Such optimal selection is currently the subject of further investigation. In particular studying the persistence (i.e. the memory) of the system with the variogram analysis (Jaquet and Carniel, 2003) could provide useful information in order to optimize the choice of the length of the time windows involved in the forecast (Carniel et al., 2006).

Another result of the statistical analysis presented in this paper is the fact that there are no statistically significant indications suggesting that events located inside the island can be forecasted more easily than the ones outside, or vice versa.

The main interpretation of all the results presented here is that the seismic noise, notwithstanding its strong anthropogenic contamination, contains significant information about the forthcoming tectonic events, i.e. it must have a significant fraction with a "volcanic" origin, where the term "volcanic" has to be considered in a wide sense, including both directly magmatic effects and indirect effects, as discussed below. In fact, no examples are known in a purely tectonic setting, where the occurrence of purely tectonic events can be forecasted by using continuous seismic noise recorded nearby.

Regarding the process generating this tremor, although of course the data we have cannot yet proof this hypothesis, we can speculate that its appearance is possibly due to the start of a convective process in the phonolitic magma chamber of the Teide - Pico Viejo complex, triggered by the arrival of a basaltic magma batch. The tremor could be the direct footprint of this convection, or be an indirect indication, e.g. filtered by the interaction with the superficial aquifer(s). More geophysical data are definitely needed to verify the reliability of this hypothesis, and a continuous monitoring is essential in order to determine the possible evolution of the current 
situation. In fact, several options are possible for the future evolution, including the possibility that this is a temporary disequilibrium state that would not evolve into an eruption but rather return to a new stable state. However, it is important to stress that the comparison of statistics computed for 2004 and 2005 data clearly indicate that there is not a decreasing trend between 2004 and 2005, i.e. this disequilibrium state is still observed. Regarding the determination of the exact link (is it a cause-effect relationship? are they two effects of the same cause?) between the tremor and the earthquakes, link that that must exist to explain the successful forecasts, further research is surely needed. An intriguing hypothesis (S. De la Cruz-Reyna, personal communication) suggests a bidirectional link between the two. In the plots of 1/SSEM versus time, it may be likely to trace also upwards lines from the earthquakes to the following ascending parts of the 1/SSEM curve, before the maxima. This could be interpreted as earthquakes releasing crustal strain energy, effect that is translated in a reduction of the local level of tremor in the volcanic zone. Energy accumulated for the lack of tremor release would in turn produce an increase in the tremor, producing the maximum in the 1/SSEM curve. The descending part would point towards the next earthquake of this cycle.

In summary, we claim that we are in presence of a single process that both contributes to the generation of the seismic noise and to the generation of the tectonic events - both inside the island and close to the island -, a process as far as we know never previously observed in Tenerife and which may be related to a reawakening of the Teide - Pico Viejo volcanic system.

Acknowledgements. The authors wish to thank W. Aspinall, M. J. Blanco, J. Ibáñez, J. Neuberg, F. Barazza, E. Del Pin, M. Di Cecca, A. Quintero, S. Falsaperla, T. Correig, J. Vila and M. J. Gonzalez Fuentes for useful discussions. The mainteinance of the seismic stations would be impossible without the local logistic support of the Ayuntamiento de Icod de Los Vinos and without the support of the Accion Complementaria TEGETEIDE, Técnicas geofísicas y geodésicas para el studio de la zona volcánica activa Teide-Pico Viejo, Tenerife, a project funded by Spanish Ministry of Education and Science, contract CGL2004-21643-E and coordinated by A. García. The statistical program $\mathrm{R}$ was used for the seasonal decomposition. The suggestions of the Editor J. Martí and of the referees S. De la Cruz-Reyna and O. Jaquet have led to considerable improvement of the manuscript.

Edited by: J. Martí

Reviewed by: S. De la Cruz-Reyna and O. Jaquet

\section{References}

Ablay, G. J., Ernst, G. G. J., Martí, J., and Sparks, R. S. J.: The 2 ka subplinian eruption of Montaña Blanca, Tenerife, Bull. Volcanol., 57, 337-355, 1995.

Ablay, G. J. and Martí , J.: Stratigraphy, Structure, and Volcanic Evolution of the Pico Teide-Pico Viejo Formation, Tenerife, Canary Islands, J. Volcan. Geotherm. Res., 103, 175-208, 2000.
Almendros, J., Ibáñez, J., Alguacil, G., Morales, J., Del Pezzo, E., La Rocca, M., Ortiz, R., Araña, V., and Blanco, M. J.: A Double Seismic Antenna Experiment at Teide Volcano: Existence of Local Seismicity and Lack of Evidences of Volcanic Tremor, J. Volcan. Geotherm. Res., 103, 439-462, 2000.

Almendros, J., Luzon, F., and Posadas, A.: Microtremor analyses at Teide Volcano (Canary Islands, Spain): Assessment of natural frequencies of vibration using time-dependent horizontal-tovertical spectral ratios, Pure Appl. Geophys., 161(7), 1579-1596, 2004.

Ancochea, E., Fúster, J. M., Ibarrola, E., Cendrero, A., Coello, J., Hernán, F., Cantagrel, J. M., and Jamond, C.: Volcanic evolution of the island of Tenerife (Canary Islands) in the light of new K-Ar data, J. Volcanol. Geotherm. Res., 44, 231-249, 1990.

Araña, V.: Litología y estructura del Edificio Cañadas, Tenerife (Islas Canarias), Estudios Geológicos, XXVII, 95-135, 1971.

Araña, V., Felpeto, A., Astiz, M., García, A., Ortiz, R., and Abella, R.: Zonation of the main volcanic hazards (lava flows and ash fall) in Tenerife, Canary Islands. A proposal for a surveillance network, J. Volcanol. Geothermal Res., 103, 377-391, 2000.

Carniel, R. and Di Cecca, M.: Dynamical tools for the analysis of long term evolution of volcanic tremor at Stromboli, Ann. Geofis., 42, 3, 483-495, 1999.

Carniel, R., Di Cecca, M., and Rouland, D.: Ambrym, Vanuatu (July-August 2000): Spectral and dynamical transitions on the hours-to-days timescale, J. Volcanol. Geothem. Res., 128, 1-3, $1-13,2003$.

Carniel, R., Ortiz, R., and Di Cecca, M.: Spectral and dynamical hints on the timescale of preparation of the 5 April 2003 explosionat Stromboli volcano, Can. J. Earth Sci., 43, 41-55, 2006.

Carniel, R., Tárraga, M., Jaquet, O., and García, A.: On the memory of seismic noise recorded at Teide - Pico Viejo volcanic complex, Tenerife, Spain, EGU06-A-01929; NH5.03-1WE2P-0679, EGU General Assembly, Vienna, April 2006.

Chastin, S. F. M. and Main, I. G.: Statistical analysis of daily seismic event rate as a precursor to volcanic eruptions, Geophys. Res. Lett., 30, 13, 1671, doi:10.1029/2003GL016900, 2003.

Cleveland, R. B., Cleveland, W. S., McRae, J. E., and Terpenning, I.: STL: A Seasonal-Trend Decomposition Procedure Based on Loess, J. Official Statistics, 6, 3-73, 1990.

Cornelius, R. R. and Voight, B.: Graphical and PC-software analysis of volcano eruption precursors according to the Materials Failure Forecast Method (FFM), J. Volcanol. Geotherm. Res., 64, 295-320, 1995.

De la Cruz-Reina, S. and Reyes-Dávila, G.: A model to describe precursory material-failure phenomena: application to shortterm forecasting at Colima volcano, Mexico, Bull. Volcanol., 63, 297-308, 2001.

Del Pezzo, E., La Rocca, M., and Ibáñez, J.: Observations of highfrequency scattered waves using dense arrays at Teide volcano, Bull. Seismol. Soc. Am., 87, 1637-1647, 1997.

Endo, T. E. and Murray, T.: Real-time Seismic Amplitude Measurement (RSAM). A volcano monitoring and prediction tool, Bull. Volcanol., 53, 533-545, 1991.

Falsaperla, S., Alparone, S., and Spampinato, S.: Seismic features of the June 1999 tectonic swarm in the Stromboli volcano region, Italy, J. Volcanol. Geotherm. Res., 125, 1-2, 121-136, 2003.

García, A., Vila, J., Ortiz, R., Macia, R., Sleeman, R., Marrero, J. M., Sánchez, N., Tárraga, M., and Correig, A. M.: Monitoring 
the reawakening of Canary Islands' Teide volcano, EOS, 87, 6, 61-72, 2006.

Jaquet, O. and Carniel, R.: Multivariate stochastic modelling: towards forecasts of paroxysmal phases at Stromboli, J. Volcanol. Geotherm. Res., 128, 1-3, 261-271, 2003.

Marrero, J. M, Tárraga, M., and Ortiz, R.: Analysis by means of Markov matrix of seismic activity in an active caldera: application to the seismic crisis of Tenerife 2004. Workshop "Caldera Volcanism: Analysis, Modelling and Response", Parador de Las Cañadas. Tenerife, conveners: Martí J. and Gottsmann, J., Spain, 16-22 October, 2005.

Martí, J., Mitjavila, J., Araña, V.: Stratigraphy, structure and geochronology of the Las Cañadas caldera (Tenerife, Canary Islands), Geol. Mag., 131, 715-727, 1994.

Martí, J. and Gudmundsson, A.: The Las Cañadas caldera (Tenerife, Canary Island): an overlapping collapse caldera generated by magma-chamber migration, J. Volcanol. Geothem. Res., 103, 161-173, 2000.

Mc Nutt, S. R.: Seismic monitoring and eruption forecasting of volcanoes: a review of the state-of-the-art and case histories, in: Monitoring and mitigation of volcano hazards, edited by: Scarpa, R. and Tilling, R., Springer-Verlag Berlin Heidelberg, 100-146, 1996.
Mezcua, J., Buforn, E., Udías, A., and Rueda, J.: Seismotectonics of the Canary Islands, Tectonophysics, 208, 447-452, 1992.

Nakamura, Y.: A method for dynamic characteristics estimation of subsurface using microtremor on the ground surface, Q. Rept. Railway Tech. Res. Inst., 30, 25-33, 1989.

Ortiz, R., Moreno, H., García, A., Fuentealba, G., Astiz, M., Peña, P., Sánchez, N., and Tárraga, M.: Villarrica Volcano (Chile): Characteristics of the volcanic tremor and forecasting of small explosions by means of materials failure method, J. Volcanol. Geotherm. Res, 128, 1-3, 247-259, 2003.

Ortiz, R., García, A., and Astiz, M.: Instrumentación en Volcanología, Servicio de Publicaciones del Cabildo Insular de Lanzarote, Madrid, ISBN: 84-87021-84-0, 345 pp., 2001.

Rogers, J. A. and Stephens, J. A.: SSAM Real Time Seismic Spectral Amplitude Measurement on PC and its application to volcano monitoring, Bull. Seism. Soc. Am., 85, 632-639, 1995.

Voight, B.: A method for prediction of volcanic eruptions, Nature, 332, 10, 125-130, 1988.

Voight, B.: A relation to describe rate-dependent material failure, Science, 243, 200-203, 1989.

Voight, B. and Cornelius, R. R.: Prospects for eruption prediction in near real-time, Nature, 350, 695-698, 1991. 